\title{
Phase I/II study on kilovoltage surface brachytherapy in conjunctival cancer: preliminary results
}

\author{
Gustavo R Sarria', Gustavo J Sarria ${ }^{1}$, Paola Fuentes Rivera ${ }^{1}$, Mayer Zaharia ${ }^{1}$, Solón Serpa ${ }^{2}$ and Mario Buitrago ${ }^{2}$ \\ ${ }^{1}$ Radiotherapy Department, National Institute of Neoplastic Diseases (INEN), Lima 15038, Peru \\ ${ }^{2}$ Ophthalmic Oncology Department, National Institute of Neoplastic Diseases (INEN), Lima 15038, Peru
}

Correspondence to: Gustavo R Sarria Email: Gustavo_sarria@yahoo.com and gsarria97@gmail.com

\begin{abstract}
Introduction: In ocular conjunctival carcinoma after surgery, adjuvant treatment has a role and kilovoltage surface brachytherapy opens a new door for the range of therapeutic options.

Materials and methods: Between October 2014 and June 2017, at the National Institute of Neoplastic Diseases (INEN) from Peru, 39 patients with squamous cell carcinoma of ocular conjunctiva, T1-T3, resected, were selected to receive adjuvant treatment. The portable accelerator of 50-kV INTRABEAM (Carl Zeiss Meditec) was used, after local anaesthesia and blocking of ocular muscles movement. The doses used were $18 \mathrm{~Gy}$ for patients with free margins and $22 \mathrm{~Gy}$ for positive edges, according to calculation of equivalent dose of $2 \mathrm{~Gy}$ per fraction of 46 and $66 \mathrm{~Gy}$, respectively, assuming a tumoural $\alpha / \beta$ ratio of 8 Gy. The prescription was done to 2 mm depth.
\end{abstract}

Results: The median age was 69 years, distributed evenly between both genders, with a median follow-up of 12 months. The surgical margins were $59 \%$ free and $41 \%$ committed, with no difference between the institutions where the surgery was performed $(P=0.069)$. The median tumour size was $7 \mathrm{~mm}$ with $2 \mathrm{~mm}$ of invasion, $61.5 \%$ was T2 and $35.9 \% \mathrm{~T} 1$. The mean time between surgery and irradiation was 1.5 months, $23.1 \%$ of patients developed grade I toxicity of spontaneous resolution, without evidence of greater degree in any case. The dose had no statistical relationship with toxicity $(P=0.533)$. One-year disease-free survival was $96.7 \%$.

Conclusions: Kilovoltage surface brachytherapy is an applicable and reproducible tool in the treatment of squamous cell carcinoma of ocular conjunctiva. The administered doses are well tolerated by patients with low levels of acute toxicity. Longer follow-up is needed to establish disease control rates and late toxicities.

Keywords: surface brachytherapy, kilovoltage, conjunctival carcinoma

Published: 15/05/2018

Received: 19/10/2017

ecancer 2018, 12:835 https://doi.org/10.3332/ecancer.2018.835

Copyright: (C) the authors; licensee ecancermedicalscience. This is an Open Access article distributed under the terms of the Creative Commons Attribution License (http://creativecommons.org/licenses/by/3.0), which permits unrestricted use, distribution, and reproduction in any medium, provided the original work is properly cited. 


\section{Introduction}

Conjunctival squamous cell carcinoma is the second most frequent malignant ocular tumour [1, 2, 3]. The bulbar conjunctiva is where this disease most frequently presents itself, and it may have a poor prognosis if it is not diagnosed and treated early. Newton et al [4] found that the rate of conjunctival squamous cell carcinoma decreases by approximately $49 \%$ for every $10 \%$ increase in latitude. For example, Uganda exhibits 12 new cases per million inhabitants per year, whereas England has a rate of 0.2 new cases per million inhabitants per year $[4,5]$. In studies conducted in the United States, the rate was 0.3 patients per million inhabitants per year [4].

Amongst the Peruvian population, according to the available data from the Lima Metropolitan Cancer Registry 2010-2012, there were 157 new cases in this selected period, 83 in males and 74 in females, with the population over 70 years of age being the most affected. There are currently no national statistics [6].

Currently, the primary operation is surgical resection, which identifies various adjuvant tools such as cryotherapy, topical chemotherapy and radiotherapy in its various forms (external radiotherapy and/or brachytherapy), to improve disease-free survival according to various reports $[1,7]$. Originally, brachytherapy was administered with plates of radioactive isotopes, which remained in contact with the surface that was to be treated for different times, depending on the rate of the emitted dose and required depth [8].

This study seeks to determine the usefulness of single-dose surface kilovoltage brachytherapy, analysing the applicability, toxicity and disease control rates which it could provide.

\section{Objectives}

\section{Main objectives}

To establish the rate of acute complications in patients diagnosed with conjunctival squamous cell carcinoma, T1-T3, who are undergoing kilovoltage surface brachytherapy.

To establish the optimum tolerable dose of treatment in patients diagnosed with conjunctival squamous cell carcinoma, T1-T3, undergoing kilovoltage surface brachytherapy.

\section{Secondary objectives}

To discover the 5-year disease-free survival rate in patients diagnosed with ocular conjunctival squamous cell carcinoma, T1-T3, undergoing kilovoltage surface brachytherapy.

\section{Hypothesis}

The rate of acute complications in patients with a diagnosis of conjunctival squamous cell carcinoma, who were operated on and who underwent kilovoltage surface brachytherapy, is acceptable.

The optimal tolerated single-fraction dose of treatment is equivalent to 46 Gy and 66 Gy, according to the status of surgical margins, at fractions equivalent to $2 \mathrm{~Gy}$, by applying the linear-quadratic model.

The 5-year disease-free survival rate is comparable with the historical reports of treatment with external radiotherapy.

\section{Materials and methods}

Between October 2014 and June 2017, 39 patients diagnosed with conjunctival squamous cell carcinoma T1-T3, who underwent surgical resection, but not topical chemotherapy nor any other nonradiotherapy treatment, received adjuvant therapy with surface brachytherapy on the operating table in one single application. 
The patients' position was set by placing thermoplastic masks, fenestrated on the patient's ocular region. Eye movements were limited by blocking the extrinsic musculature of the eyeball, and the tissues were exposed with a blepharostat, with prior local surface anaesthesia with drops. The portable 50-kV INTRABEAM accelerator (Carl Zeiss Meditec) was used, with Flat Applicators with a variable diameter of between 1 and $2 \mathrm{~cm}$, depending on the characteristics of the injury treated.

The doses prescribed were 18 and $22 \mathrm{~Gy}$, according to the status of surgical margins; free or compromised, respectively. A radiobiological equivalent of $2 \mathrm{~Gy} /$ fraction was established, assuming a tumoural $\alpha / \beta$ ratio of $8 \mathrm{~Gy}$. This is generally the value related to head and necksquamous cell carcinoma. The dose was calculated using the formula:

$$
\mathrm{EQD2}=D \cdot \frac{d+(\alpha / \beta)}{2 G y+(\alpha / \beta)},
$$

based on the linear-quadratic model, and equivalent values of 46.8 and $66 \mathrm{~Gy}$ at $2 \mathrm{~Gy} /$ fraction were obtained. The prescribed dose was administered at a depth of $2 \mathrm{~mm}$, in relation to the thickness of the ocular structures.

The toxicity was evaluated according to the Common Terminology Criteria for Adverse Events (CTCAE) v4.03.

\section{Ethical considerations}

The application of treatment was under the express authorisation of the patient by signed informed consent, with full knowledge of potential adverse effects from the use of radiation, which is recorded in the clinical history.

\section{Statistical analysis}

A descriptive analysis of the data was carried out through frequencies, percentages and summary measures (average, media and range). Using the Chi-square test, the association amongst qualitative characteristics was evaluated, using Yates' correction where necessary.

Differences between groups with a qualitative characteristic with reference to quantitative characteristics were evaluated with the $t$-test for independent samples (by a normality test of these characteristics), or its corresponding nonparametric test. A $P$-value $<0.05$ was considered for an association or significant difference. The statistical analysis used R software [R Core Team (2017). R: a language and environment for statistical computing. R Foundation for Statistical Computing, Vienna, Austria. URL: https://www.R-project.org/].

\section{Results}

The clinical (Table 1), treatment (Table 2) and pathological characteristics (Table 3) of 39 patients with conjunctival squamous cell carcinoma are described. All patients were alive at the time of evaluation. The distribution by $T$ classification was $35.9 \%$ for $\mathrm{T} 1,61.5 \%$ for $\mathrm{T} 2$ and $2.6 \%$ for T3. Frequency by years of treatment with INTRABEAM is shown in Figure 1 (recorded until June 2017). Nine patients (23.1\%) with acute complications were documented (Figure 2). All patients were grade G1 and spontaneous resolution within the first-month post-treatment. In all cases, there was erythema or mild itching. No late toxicity has been found so far. It was found that the status of the margins and the place of surgery are not associated (Figure 3). Figure 4 shows that the status of margins and complications are independent; their association with the T stage could not be evaluated (Figure 5), nor was an association between the dose and the complications observed (Figure 6). In the group of patients with no complications, the average tumour size was $7.62 \mathrm{~mm}$ (range 2-20 mm) and in the group with complications, the size was $8.39 \mathrm{~mm}$ (range 1.5-20 mm). A significant difference was not found between the two groups in terms of size $(P=0.701)$.

The median follow-up time was 12 months, with a minimum of 3 months and a maximum of 31 months. Only one patient, with compromised surgical margins, presented a recurrence of disease during follow-up 7 months after having undergone treatment. One-year disease-free survival was $96.7 \%$, at the time there being no recurrence of disease in the patients with a longer follow-up time (Figure 7).

\section{Discussion}

In health systems such as that in Peru, the administration of shortened treatment is introduced as an attractive alternative to reduce costs, without affecting the patients' quality of care. In addition, the limited accessibility to radiotherapy services, both in Peru as well as in the rest 
of the region, and the prolonged residence of patients far from their home, represent an additional cost that is not financed by the health system, but rather by the patient or family themselves [9].

Table 1. Clinical features.

\begin{tabular}{|c|c|c|}
\hline & $\mathbf{N}$ & $\%$ \\
\hline Age, years & \multicolumn{2}{|c|}{} \\
\hline Average/median/range & \multicolumn{2}{|c|}{$63.64 / 69 /[29-87]$} \\
\hline Gender & & \\
\hline Female & 19 & 48.7 \\
\hline Male & 20 & 51.3 \\
\hline Side & & \\
\hline Right & 18 & 46.2 \\
\hline Left & 21 & 53.8 \\
\hline
\end{tabular}

Table 2. Treatment features.

\begin{tabular}{|l|c|c|}
\hline & N & $\%$ \\
\hline Surgery type & & \\
\hline Biopsy & 4 & 10.3 \\
\hline Local wide excision & 35 & 89.7 \\
\hline Place of surgery & & \\
\hline INEN & 19 & 48.7 \\
\hline Other institution & 20 & 51.3 \\
\hline $\begin{array}{l}\text { Time between surgery and IB, } \\
\text { months }\end{array}$ & & \\
\hline Average/median/range & $1.821 / 1.5 /[0-5]$ \\
\hline Dosis cGy & \multicolumn{2}{|c|}{} \\
\hline 1800 & 23 & 59.0 \\
\hline 2200 & 16 & 41.0 \\
\hline
\end{tabular}

Table 3. Pathological features.

\begin{tabular}{|l|c|c|}
\hline & N & $\%$ \\
\hline Borders & & \\
\hline Negative & 23 & 59.0 \\
\hline Positive & 16 & 41.0 \\
\hline Size, mm & \multicolumn{2}{|l|}{} \\
\hline Average/median/range & $7.795 / 7 /[1.5-20]$ \\
\hline T & \multicolumn{2}{|}{} \\
\hline T1 & 14 & 35.9 \\
\hline T2 & 24 & 61.5 \\
\hline T3 & 1 & 2.6 \\
\hline Depth, mm $(N=19)$ & & \\
\hline Average/median/range & & $2.2 / 2 /[0.1-6]$ \\
\hline
\end{tabular}




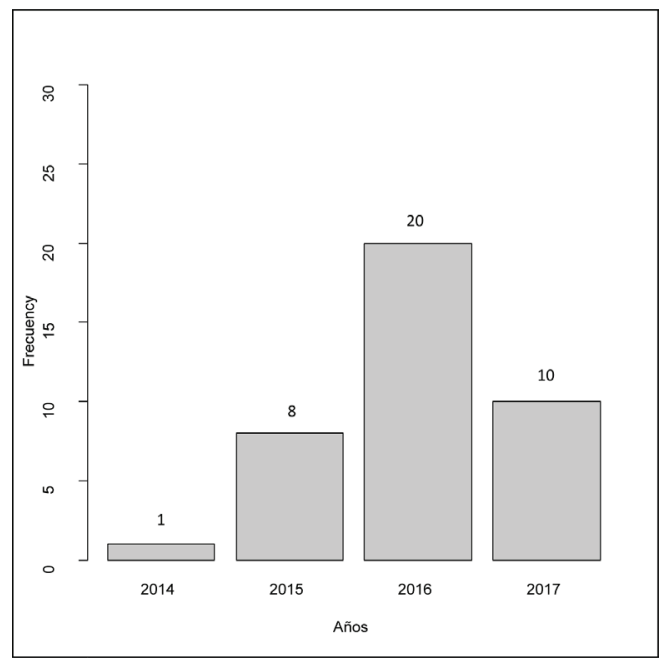

Figure 1. Frecquency per years of IB applications.

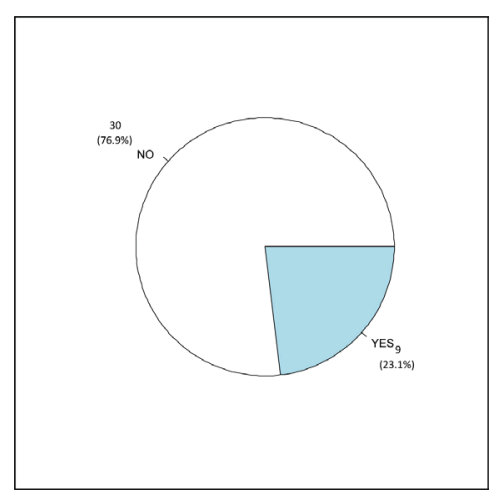

Figure 2. Complications rate.

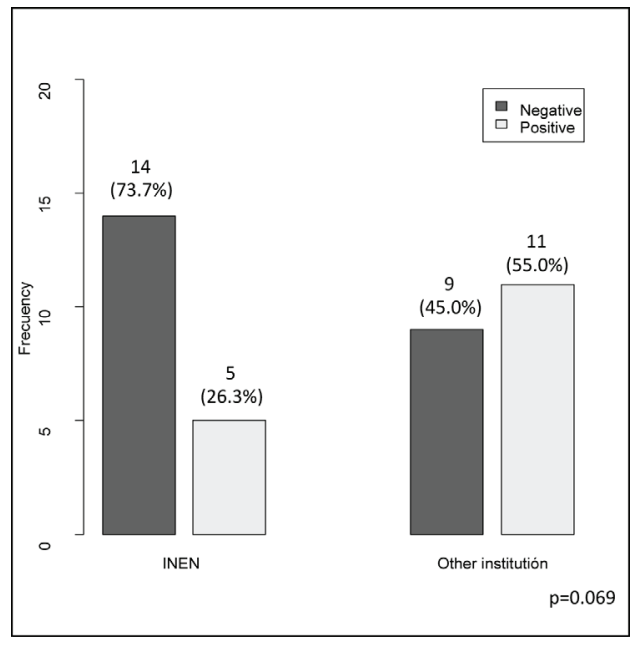

Figure 3. Borders status (negative/positive) according to surgery place. 


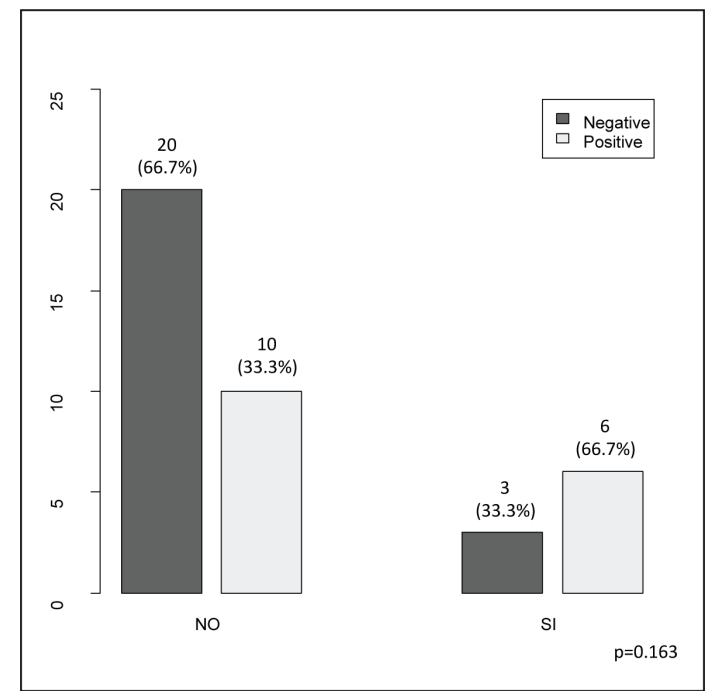

Figure 4. Borders status (negative/positive) according to the presence of complications (no/yes).

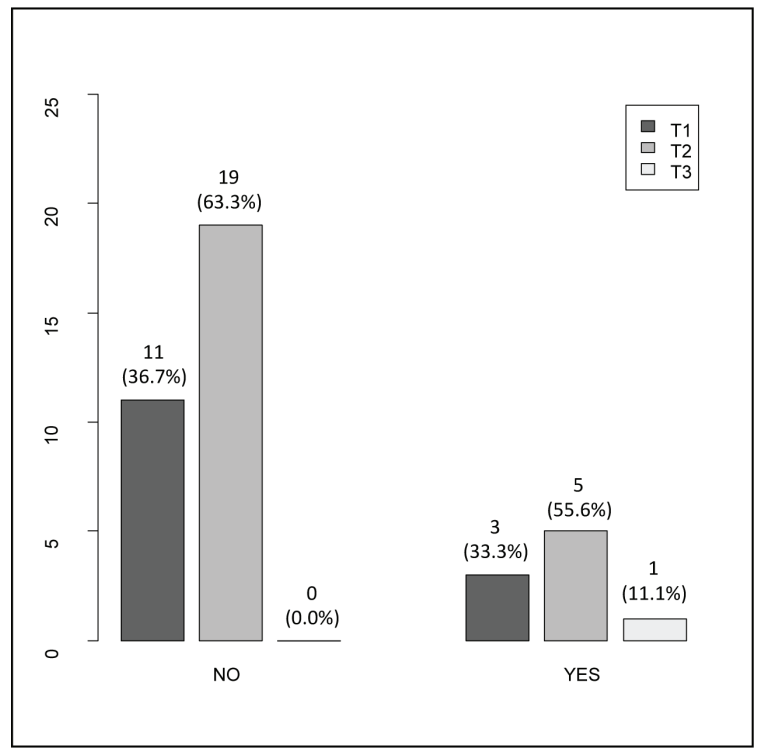

Figure 5. T stage (T1/T2/T3) according to the presence of complications (no/yes). 
ecancer $2018,12: 835$

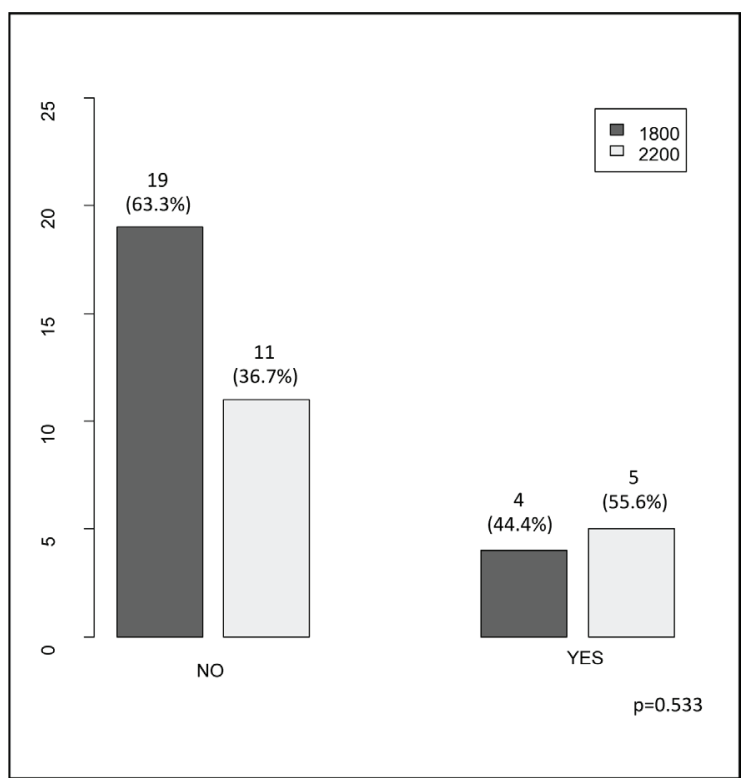

Figure 6. Dosis (1800 cGy/2200 cGy) according to the presence of complications (no/yes).

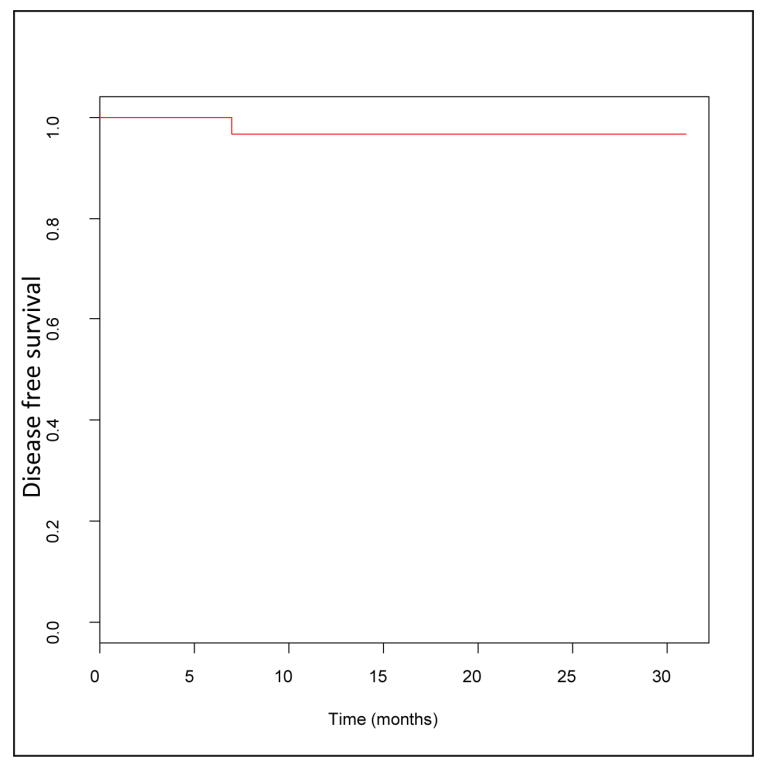

Figure 7. Estimated disease free survival curve.

The need for adjuvant therapy in conjunctival squamous cell carcinoma is imperative, given the results of disease control at the international level, compared to surgery alone. Galor et al [7] published a retrospective series of 389 patients who underwent local resection of ocular surface carcinomas in 2012 , establishing risk factors for local recurrence. It presents figures of $10 \%$ recurrence in the first year follow-up and $21 \%$ at 5 years. It Identifies that T2 and T3 have a greater probability of recurrence than T1 using (T2/T1 hazard ratio [HR], 2.05 $[P=0.04]) \mathrm{T} 3 / \mathrm{T} 1 \mathrm{HR}, 2.31(P=0.07)$, the Tarsus HR compromise, 4.12; $P=0.007$. Treatment with adjuvant cryotherapy decreases the rate of recurrence significantly in patients with compromised margins, $\mathrm{HR}, 0.51 ; P=0.03$, bringing the value of resected neoplasms with free 
margins to around $10 \%$ control in 5 years [7]. In successive series such as that of Laskar et al [10], it is demonstrated that patients subject to resection with free margins can reach recurrence rates up to $33 \%$, whilst patients with compromised margins reach up to $56 \%$. In their work, they reported treatment with strontium plates at variable dosage, taking averages of $44 \mathrm{~Gy}$, in daily doses of $4 \mathrm{~Gy}$, and disease-free survival rates of $90.9 \%$ at 5 years. No patient in their publication had a toxicity greater than or equal to grade II [10]. Kearsley et al [11] in 1988 reported interesting results for the use of kilovoltage at variable dosage between 45 to $50 \mathrm{~Gy}$ in 8 to 15 fractions and a single fraction of $10 \mathrm{~Gy}$, without recurrences in the treated patients, with follow-up periods exceeding 10 years and grade I early and late toxicities [11]. In our institute, retrospective figures of 5-year disease-free survival occurred around 78.8 to $82.3 \%$, at the stage of post-surgery adjuvant external radiation, with daily doses of $2 \mathrm{~Gy} /$ fraction and variable totals between 45 and $66 \mathrm{~Gy}$, according to the status of surgical margins.

The application of one single session of surface brachytherapy greatly decreases the potential errors of configuration and positioning, amongst others, which are subject to variation by daily treatments, achieving equivalent doses for disease control that have even greater biological value, given its nature [12].

The procedure performed proved to be highly reproducible for the treated patients. The minimal invasiveness to achieve a stable position for the eyeball is remarkable, in a similar fashion to that reported by Semenova and Finger [13].

Acute toxicity has been acceptable, within grade I, according to the criteria of the CTCAE v4.03 [14]. Every case had a spontaneous resolution within the first-month post-treatment, without the need for medical intervention. Late toxicity is not evident at this time. These findings correlate with the descriptions in the literature [10,11], achieving dose escalation suitable for disease control. The use of kilovoltage allows for a more predictable dosimetry compared to radioactive isotopes and eliminates the unnecessary exposure of patients and health personnel to ionising radiation. To date, our Institution has replaced the use of isotopes for surface treatment, in line with the international trend towards migration to more secure systems of treatment, which allow for versatility in pathology management of other anatomical regions [15].

One constraint is that the study is being carried out in only one institution. The support of other centres on a global level would deliver more legitimacy and statistical validity to the obtained results.

The preliminary results of disease-free survival are encouraging, taking into account the recurrent nature of this entity. However, it is premature to draw conclusions regarding the rates of control, given the short follow-up time to date. A long-term follow-up is necessary in order to determine the real impact value of this form of treatment, such as the toxicity that could present itself over time.

\section{Conclusions}

The use of kilovoltage in the management of conjunctival squamous cell carcinoma is reproducible, viable and safe, according to the experience of our Institution. Acute toxicity, as a consequence of the treatment, is acceptable when compared to the potential benefits offered by this method. The support of other international centres in this investigation is important to reach a greater case volume and improve the strength of this study. A greater follow-up period is needed to determine long-term late toxicities and disease-free survival rates in the group of patients who were analysed.

\section{Conflicts of interest}

The participants stated that they had no conflicts of interest.

\section{Acknowledgments}

To Dr Mayer Zaharia Bassan, who in life actively contributed to the completion of this study. 


\section{References}

1. Karcioglu Z (2015) Orbital Tumors: Diagnosis and Treatment (New York: Springer) pp 447-467

2. Shields J, Shields C, and Gunduz K, et al (1999) The 1998 Pan American LECTURE. Intraocular invasion of conjunctival squamous cell carcinoma in five patients Ophthal Plastic Reconstr Surg 15(3) 153-160 PMID: 10355832

3. Shields C and Shields JA (2004) Tumors of the conjunctiva and cornea Surv Ophthalmol 49(1) 3-24 https://doi.org/10.1016/j.survophthal.2003.10.008 PMID: 14711437

4. Newton R, Ziegler J, and Ateenyi-Agaba C, et al (2003) Erratum: the epidemiology of conjunctival squamous cell carcinoma in Uganda Br J Cancer 89(2) 423-423 https://doi.org/10.1038/sj.bjc.6601128

5. Tabin G, Levin S, and Snibson G, et al (1997) Late recurrences and the necessity for long-term follow-up in corneal and conjunctival intraepithelial neoplasia Ophthalmol 104(3) 485-492 https://doi.org/10.1016/S0161-6420(97)30287-5

6. Payet E et al (2016) Registro de Cáncer de Lima Metropolitana, Incidencia y Mortalidad 2010-2012 vol 5 (Lima) pp 43-47

7. Galor A, Karp C, and Oellers P, et al (2012) Predictors of ocular surface squamous neoplasia recurrence after excisional surgery Ophthalmol 119(10) 1974-1981 https://doi.org/10.1016/j.ophtha.2012.04.022

8. Gagne N and Rivard M (2013) COMS eye plaque brachytherapy dosimetric sensitivity to source photon energy and seed design Appl Radiat Isot 79 62-66 https://doi.org/10.1016/j.apradiso.2013.04.034

9. Amendola B, Quarneti A, and Rosa A, et al (2017) Perspectives on patient access to radiation oncology services in south america Semin Radiat Oncol 27(2) 169-175 https://doi.org/10.1016/j.semradonc.2016.11.009 PMID: 28325244

10. Laskar S, Gurram L, and Laskar S, et al (2015) Superficial ocular malignancies treated with strontium-90 brachytherapy: long term outcomes J Contemp Brachytherapy 5 369-373 https://doi.org/10.5114/jcb.2014.55003

11. Kearsley J, Fitchew R, and Taylor R (1988) Adjunctive radiotherapy with strontium-90 in the treatment of conjunctival squamous cell carcinoma Int J Radiat Oncol Biol Phys 14(3) 435-443 https://doi.org/10.1016/0360-3016(88)90257-X PMID: 3343150

12. Ouhib Z, Kasper M, and Perez Calatayud J, et al (2015) Aspects of dosimetry and clinical practice of skin brachytherapy: the American Brachytherapy Society working group report Brachytherapy 14(6) 840-858 https://doi.org/10.1016/j.brachy.2015.06.005 PMID: 26319367

13. Semenova $E$ and Finger $P$ (2013) Amniotic membrane corneal buffering during plaque radiation therapy for anterior uveal melanoma Ophthalmic Surg Lasers Imaging Retina 44(5) 477-482 https://doi.org/10.3928/23258160-20130909-10 PMID: 24044711

14. Chen A, Setser A, and Anadkat M, et al (2012) Grading dermatologic adverse events of cancer treatments: The Common Terminology Criteria for Adverse Events Version 4.0 J Am Acad Dermatol 67(5) 1025-1039 https://doi.org/10.1016/j.jaad.2012.02.010 PMID: 22502948

15. Palmer A, Pearson M, and Whittard P, et al (2016) Current status of kilovoltage (kV) radiotherapy in the UK: installed equipment, clinical workload, physics quality control and radiation dosimetry Br J Radiol 89(1068) 20160641 https://doi.org/10.1259/ bjr.20160641 PMID: 27730839 PMCID: $\underline{5604929}$ 